Qualitative study-other

\section{Compassion is an essential component of good nursing care and can be conveyed through the smallest actions}

10.1136/eb-2014-102025

\section{Katherine Curtis}

University of Surrey, School of Health Sciences, Surrey, UK

Correspondence to: Dr Katherine Curtis, University of Surrey, School of Health Sciences, DK Building Guildford, Surrey GU2 7TE, UK; k.curtis@ surrey.ac.uk

Commentary on: Bramley L, Matiti M. How does it really feel to be in my shoes? Patients' experiences of compassion within nursing care and their perceptions of developing compassionate nurses. J Clin Nurs 2014;23:2790-9.

\section{Implications for practice and research}

- Patients' experiences of compassion and lack of compassion contribute to current understanding of complexity within compassionate nursing practice.

- Patients believe that nurses can develop compassionate practice through exposure to vignettes of their experiences.

- Further research on patient experiences could help identify how to enable 'fleeting acts' that convey compassion.

\section{Context}

Compassion is not a new concept within healthcare. ${ }^{1}$ However, compassion has become the focus of much research and debate during the past 10 years, following reports of lack of compassion within UK healthcare practice. This recent intense focus has addressed many aspects of care practices and education, recognising that compassion is a complex concept. ${ }^{2}$ This study adds a further dimension to understand the complexity of compassion, through a focus on patients' perceptions.

\section{Methods}

A qualitative descriptive study was undertaken to explore patients' experiences of their care, just prior to discharge from hospital. In order to understand patients' perceptions of what compassion is and how it can be developed, the study recruited 10 hospital patients from within six different medical wards. The participants comprised both males and females and they agreed to individual and in-depth interviews about their experiences of compassion. Digital recordings of the interviews were transcribed and thematically analysed, with facilitators and inhibitors to compassion being identified within the data. Ethical research practice was upheld throughout and the research process met all the requirements for credibility and trustworthiness.

\section{Findings}

Three main themes were found within the data: (1) patients saw compassion as based on acts that demonstrated human relationships "knowing me and giving me your time'; (2) patients believed the impact of compassion was a sense of empathising with their situation or 'being in their shoes'; (3) compassion was the essence of nursing and required communication alongside inherent values-based care.

\section{Commentary}

The study provides a further contribution to understand compassion within healthcare practice through the patient's experience and to promot and develop compassionate nursing.

During the past 10 years, reports of poor standards of care and outright cruelty have frequently been in the press and quite rightly have caused outrage within and outside healthcare professions. Compassion has been the focus of numerous recent research studies that have led to debates on how best to promote compassion within healthcare and health professional education. Some commentators reflect longingly back to several decades ago when healthcare systems supported a different and more limited scope of practice for nursing and where organisations supported higher levels of qualified staff to patient acuity. They suggest that nursing should go back to its 'old ways'. They also suggest individual or society morality and the changes in nurse education are responsible for deficits in compassion today. However, identifying and correcting the 'fault' in the system is not as simple as some suggest. Time cannot be turned back and why would society want to when some of those 'old ways' included: parents kept away from their hospitalised children; people with mental health problems being shut way in institutions and restrained; far less sophisticated and less effective surgical and medical treatments for trauma and disease.

This study reaffirms compassion within 21st century healthcare as a complex concept. It has multiple predisposing and constraining factors within today's practice and education environments. ${ }^{3}$ Compassionate practice does not simply rely on an individual demonstrating empathy and kindness but on the moral, emotional and organisational environment within which that individual learns their caring craft. ${ }^{4}{ }^{5}$ Attempts to identify and address deficits in compassion require recognition of this complexity in order to avoid over-simplified or single focused solutions. Dr Jocelyn Cornwell explained this clearly at the Kings Fund 'One year on from Francis' event, suggesting how UK healthcare systems, within which compassion is an expectation, are perfectly designed to produce the results they currently get. ${ }^{6}$ It is therefore important to consider the findings from this study within a whole system approach to improving compassionate healthcare provision.

Competing interests None.
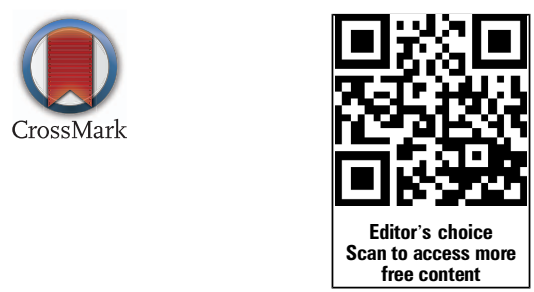

\section{References}

1. Gaut DA, Leninger MM. Caring: the compassionate healer. New York: National League for Nursing Press, 1991.

2. Schantz ML. Compassion: a concept analysis. Nurs Forum 2007;42:48-55.

3. Curtis K, Horton K, Smith P. Student nurse socialisation in compassionate practice: a Grounded Theory study. Nurse Educ Today 2012;32:790-5.

4. Smith PA. Compassion and smiles: what's the evidence? J Res Nurs 2008;13:367-70.

5. Curtis $\mathrm{K}$. Learning the requirements for compassionate practice: student vulnerability and courage. Nurs Ethics 2014;21:210-23.

6. Cornwell J. Can we design empathy into services? 2014. http://www.kingsfund.org. uk/audio-video/jocelyn-cornwell-can-we-design-empathy-services (accessed 19 Dec 2014). 